\title{
Diprosopus: A Rare Conjoined Twin
}

\author{
${ }^{1}$ Madhuri Vaidya, ${ }^{2}$ Sunita Ghike, ${ }^{3}$ Sheela Jain, ${ }^{4}$ Sulbha Joshi
}

\begin{abstract}
Diprosopus twin is a rare form of conjoined twin with incidence of one case in 180000 to 15 million births. This is a rare congenital anomaly whereby face is duplicated on the head. Usually, this type of fetuses are stillborn. A24 years unregistered primigravida presented to our hospital at 26 weeks of gestation. On clinical examination and after ultrasonography, anencephaly and polyhydramnios was diagnosed. Labor was induced considering nonviable fetus due to anencephaly. The born fetus was female baby weighing $2.2 \mathrm{~kg}$. It was a fresh stillborn with external features showing two faces, two sets of eyeballs, two sets of ears with medial ears fused, two noses and two mouths with single body. Fetus had anencephaly with proptosed eyeball. So far, very few cases are reported.
\end{abstract}

Keywords: Diprosopus, Conjoined twins, Anencephaly.

How to cite this article: Vaidya M, Ghike S, Jain S, Joshi S. Diprosopus: A Rare Conjoined Twin. J South Asian Feder Obst Gynae 2014;6(2):116-117.

\section{Source of support: Nil}

Conflict of interest: None declared

\section{INTRODUCTION}

An extremely rare congenital disorder whereby face is duplicated on the head was encountered at tertiary care hospital. It is termed as diprosopus - two-faced, because of craniofacial duplications. Although classically considered as conjoined twin, this anomaly is not normally due to fusion or incomplete separation of the two embryos. Different theories are proposed for etiopathogenesis of diprosopus twins. Very few cases are reported so far. We are reporting this case for its rarity.

\section{CASE REPORT}

A 24-year-old married since one year, primigravida with 26 weeks of gestation was referred to our hospital. She was not registered at obstetrics OPD. She had amenorrhea since 7 months. There was no complaint of pain in abdomen or bleeding per vaginum. There was no significant past or

\footnotetext{
${ }^{1,3}$ Assistant Professor, ${ }^{2}$ Professor, ${ }^{4}$ Professor and Head

${ }^{1-4}$ Department of Obstetrics and Gynecology, NKP Salve Institute of Medical Sciences and Lata Mangeshkar Hospital Nagpur, Maharashtra, India

Corresponding Author: Madhuri Vaidya, Assistant Professor Department of Obstetrics and Gynecology, NKP Salve Institute of Medical Sciences and Lata Mangeshkar Hospital Nagpur-440019, Maharashtra, India, Phone: 07104236291 9595938588, e-mail: madhuri.vaidya@rediffmail.com
}

family history. On examination, her vitals were stable. On per abdominal examination, uterus was corresponding to 38 weeks with clinically polyhydramnios. Skin on abdomen was tensed and shiny. Abdomen was uniformly distended. Fetal parts were not made out easily. On per vaginal examination, cervix was anterior, effaced, $1 \mathrm{~cm}$ dilated with tensed membrane and presenting part high up. Her blood investigations were within normal limits. On ultrasonographic examination, she had single live intrauterine gestation, polyhydramnios, anencephaly and adenomatoid lesion in left hemithorax. Her blood sugar was within normal limit. Clinical diagnosis of primigravida with anencephaly with polyhydramnios was kept. Considering nonviable fetus induction of labor was done with PGE2 gel after informed consent of patient and her relatives. Patient delivered with active management of third stage of labor. The fetus was female baby weighing $2.2 \mathrm{~kg}$. Its external features showed two faces, two eyeballs, two noses, two mouths, two sets of ears with medial ears fused and single body. Fetus had anencephaly with proptosed eyeballs (Figs 1 and 2). It was a fresh stillbirth.

\section{DISCUSSION}

Diprosopus twins ( $\mathrm{Di}$ - two, prosopus - faces) is a rare form of conjoined twins with incidence of $0.4 \%$ among all conjoined twins. Incidence of diprosopus twin is one case in 180,000 to 15 million births. ${ }^{4}$ First case was reported of diprosopus twins in 1884. Till date, only 35 cases are reported in the medical literature.

In Indian mythology, god 'Datta Guru' has three faces. Although classically considered as conjoined twin, this anomaly is not only due to fusion or incomplete separation

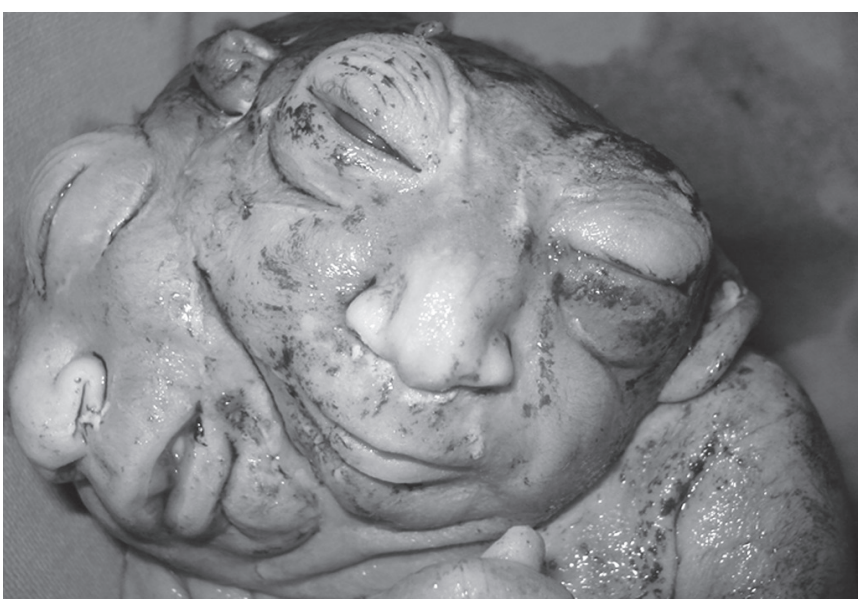

Fig. 1: Diprosopus conjoined twin 


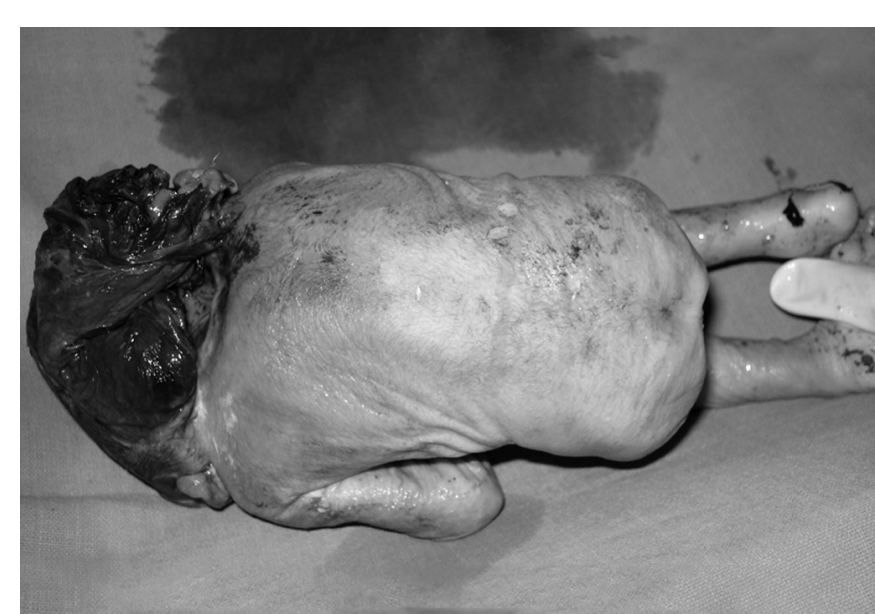

Fig. 2: Diprosopus conjoined twin with anencephaly

of two embryos. There are many proposed theories for etiopathogenesis. The SHH (Sonic HedgeHog Homolog) protein and its corresponding gene found to play an important role in signaling craniofacial pattern. During embryonic development, SHH proteins govern the width of facial tissues. In excess leads to widening of facial features and duplication of facial structures. Insufficient amount of protein leads to 'cyclopia' where facial features are insufficiently developed. ${ }^{5}$

Currently, most widely accepted theory for the formation of conjoint twins is incomplete splitting of a single embryo between 13th and 25th day of embryonic life. A commonly cited proposed etiology of diprosopus phenotype is rostral bifurcation or forking of notochord, which delineated the embryonic axis and induces neurulation. ${ }^{1}$ Diprosopus is primarily found in singleton pregnancies but can also be seen in dichorionic twins. ${ }^{4}$ Duplication of eyes is always associated with duplication of nose but nasal duplication can be isolated. ${ }^{1}$ In contrast to all other forms of conjoined twins which always have two complete notochoral axes, diprosopus might represent a genuine rostral bifurcation or duplication of the notochord. Alternatively diprosopus could be closely related to dicephalus, in which there are two completely separate but parallel notochoral axes within one vertebral column. ${ }^{2}$ In our case, there was only one notochoral axis with abnormalities in forebrain.

Duplication of eyes always implies a duplication of major portion of prosencephalon, which leads to appearance of three or four optic vesicles and one set of telencephalic vesicles, each with one rhinencephalon. Each pair of rhinencephalon would in turn induce the development of an olfactory placode, leading to two complete noses. ${ }^{7}$ This is observed in our case also.

Severe abnormalities are associated with diprosopus, like central nervous, cardiovascular, gastrointestinal and respiratory system. ${ }^{1,3}$ In our case, there was anencephaly with cystic adenomatoid lesion in lung. These malformations can be diagnosed antenatally by sonography. Polyhydramnios is the usual finding. In our case, two-dimensional sonography was done, so facial duplication was missed. It can be easily picked up by three-dimensional sonography. ${ }^{6}$

Detailed assessment of other anomalies could not be identified as autopsy was not done in our case as consent was not obtained for the same. Computed tomography, magnetic resonance imaging and MR angiography are allowed study to know the duplicative changes in diprosopus, especially for planning of cosmetic correlation. ${ }^{1}$ Usually, these fetuses are stillborn. Known instances of human with diprosopus surviving for longer than minutes to hours in the past is very rare. In 2000 and 2002, two living male infants with partial diprosopus were reported they were considered for surgical correction because of partial form of diprosopus. ${ }^{8}$

Diprosopus born in India, where Lali Singh became the most recently known person to have diprosopus like condition and survived for 2 months after birth in 2008. She was the only known individual who survived after birth. She had two sets of eyes, two noses, two mouths with cleft lip and one set of ear. Child's parents and villagers were not ready for further investigations and treatment. She died at two months of age by cardiac arrest (Miracle baby' is feted in India at BBC News accessed on 10th April 2008).

\section{REFERENCES}

1. Laor T, Stanek J, Leach JL. Diprosopus tetraophthalmus: CT as a compliment to autopsy. British J Radiol Jan 1,2012;85:10009 e10-e13.

2. Hahnel S, Schramm P, Hassfeld S, Steiner HH, Seitz A. Craniofacial duplication (diprosopus): CT, MR imaging and MR angiography finding — case report. Radiology 2003;226:210-213.

3. Rodriguez-morales EL, Correa-Rivas MS, Colon-Castillo LE. Monocephalous diprosopus, rare form of conjoined twin and associated congenital anomalies. Puerto Rico Health Sciences Journal 2002;21(3):237-240.

4. D'Armiento M, Malleti J, Maruotti GM, Martinelli P. Diprosopus conjoined twins: Radiologic autopsic and histologic study case. Fetal Pediatric Pathol 2010;29(6):431-438.

5. Hu D, Helms JA. The role of sonic Hedgehog in normal and abnormal craniofacial morphogenesis. Development 1999; 126(21):4873-4884.

6. Ulker K, Akyer SP, Temur I, Tan T, Karaka M, Gul EA. First trimester diagnosis of paraphagus diprosopus dibrachius dipus twins with craniorachischisis totalis by three-dimentional ultrasound. J Obs and Gyne Resear 2011; 10.111/j.1447-0756. 2011.01708.x from http://onlinelibrary.wiley.com.

7. Jayalakshmi S, Kumar SR, Hariharan T. Tirunelveli Medical College. A rare congenital anomaly of fetus with two faces. J Obs and Gyne of India Feb 2000;50:94-95.

8. Wu J, Staffenberg DA, Mulliken JB, Shanske AL. Diprosopus: a unique case and review of literature. Teratology $2002 \mathrm{Dec}$; 66(6):282-287. 